\title{
KURIKULUM PENDIDIKAN BAHASA DALAM PERSPEKTIF INOVASI PEMBELAJARAN
}

\author{
Maman Suryaman, Tadkiroatun Musfiroh, dan Widyastuti Purbani \\ Fakultas Bahasa dan Seni Universitas Negeri Yogyakarta \\ email: maman_suryaman@uny.ac.id
}

\begin{abstract}
Abstrak
Penelitian ini bertujuan untuk mendeskripsikan kurikulum bahasa dalam perspektif inovasi pembelajaran ditinjau dari Kerangka Kualifikasi Nasional Indonesia (KKNI) dan Standar Nasional Pendidikan Tinggi (SN-Dikti). Desain penelitian yang digunakan adalah deskriptif kualitatif dengan metode analisis isi. Sumber data berupa naskah Kurikulum Program Studi Pendidikan Bahasa Inggris dan Pendidikan Bahasa Prancis, Fakultas Bahasa dan Seni Universitas Negeri Yogyakarta. Instrumen berupa human instrument dilengkapi dengan lembar analisis untuk menelaah dokumen. Analisis data dilakukan secara deskriptif kualitatif dibantu kuantitatif. Kredibilitas penelitian dicapai melalui reliabilitas interater. Hasil penelitian ini adalah sebagai berikut. Pertama, profil lulusan belum dirumuskan berdasarkan realitas profesi yang ada di lapangan sehingga belum secara optimal dapat memberikan pemahaman tentang pengalaman belajar yang dirumuskan melalui capaian pembelajaran. Kedua, kompetensi belum dielaborasi secara lengkap dan relevan ke dalam capaian pembelajaran, profil lulusan, dan model pembelajaran. Ketiga, rumusan kompetensi sikap sudah menjadi bagian dari penyemaian dan pembentukan konsepsi dan perilaku individu tentang kesadaran identitas kebangsaan dan kenegaraan. Namun, kompetensi penguasaan pengetahuan, keterampilan khusus, dan keterampilan umum belum lengkap dan relevan dengan pembelajaran inovatif.
\end{abstract}

Kata kunci: kurikulum, pendidikan bahasa, pembelajaran inovatif

\section{LANGUAGE EDUCATION CURRICULUM IN LEARNING INNOVATION PERSPECTIVE}

\begin{abstract}
This study was aimed at describing the language education curriculum in the perspective of learning innovation at the Faculty of Languages and Arts, Yogyakarta State University in reference of Indonesian Qualifiation Framework (IQF) and National Higher Education Standards (NHES). The research design used descriptive qualitative and content analysis method. The data were obtained from the curriculum texts of English Language Education and French Language Education Study Programs. Human instrument equipped with an analysis sheet was used to review the data. The data then analyzed using the descriptive analysis method. The credibility of this study was achieved through an inter-rater reliability. The results show that: first, the profile of graduates has not been formulated based on the reality of the field profession so that it has not been able to optimally provide an understanding of learning experiences formulated through learning outcomes. Second, the competencies have not been elaborated completely and relevant into learning outcomes, graduate profiles, and learning models. Third, the formulation of attitude competencies has become part of the seeding and formation of individual conceptions and behaviors about national and state identity awareness, but the competence in mastering knowledge, special skills, and general skills is not yet complete and relevant to innovative learning.
\end{abstract}

Keywords: curriculum, language education, innovative learning 


\section{PENDAHULUAN}

Salah satu komponen akreditasi yang dinilai oleh Badan Akreditasi Nasional (BAN-PT) adalah kurikulum. Kurikulum terdapat pada standar kelima (Amir, 2010). Melalui diskusi terpumpun (FGD) dengan para ketua program studi berakreditasi B pada 17 Maret 2017 lalu, diketahui bahwa kurikulum menjadi sorotan pada semua program studi di Fakultas Bahasa dan Seni Universitas Negeri Yogyakarta (selanjutnya disingkat dengan Prodi di FBS UNY). Pada tahun 2017 ada lima Prodi FBS UNY yang masih terakreditasi B. Kelima prodi bersepakat membenahi standar 5 dengan fokus evaluasi implementasi kurikulum. Berdasarkan diskusi antara bidang akademik dengan para kaprodi, dijaring beberapa permasalahan terkait kurikulum, yakni masalah rumusan kompetensi utama, kompetensi pendukung, dan kompetensi lainnya; relevansi dengan tuntutan dan kebutuhan stakeholder; struktur dan isi kurikulum (penataan, kedalaman, keluasan, sebaran untuk transferable skills); derajat integrasi materi pembelajaran (intraantardisiplin); misi pembelajaran; dan optimalisasi sarana interaksi (pdpt.uny.ac.id dan hasil FGD dengan kaprodi, 2017).

Akreditasi dan kurikulum merupakan dua hal yang tidak terpisahkan. Berdasarkan Peraturan BAN-PT Nomor 4 Tahun 2017, kurikulum merupakan bagian dari dimensi mutu input (BAN-PT, 2017, p. 5). Alasan ini menjadi sangat berarti jika dikaitkan dengan masa berlaku kurikulum, evaluasi kurikulum secara berkala dan terencana merupakan tuntutan untuk melaksanakan koreksi terhadap peran perguruan tinggi yang bersangkutan pada dharma pendidikan, dan rekomendasi dari hasil tracer study menganjurkan perlunya evaluasi kurikulum yang relevan dengan kebutuhan masyarakat dan selalu berorientasi ke masa depan. Berdasarkan kondisi ini, tujuan penelitian ini adalah untuk mendeskripsikan kurikulum bahasa dalam perspektif inovasi pembelajaran dari sisi relevansi antara kompetensi Sikap (S), Penguasaan Pengetahuan (PP), Keterampilan Khusus (KKh), keterampilan Umum (KU) dengan Capaian Pembelajaran (CP), Model Pembelajaran (MP), dan Profil Lulusan (PL) di FBS UNY ditinjau dari KKNI dan SN-Dikti.

\section{METODE}

Penelitian ini menggunakan pendekatan kualitatif dan kuantitatif. Sumber data berupa naskah kurikulum program studi di FBS UNY, yakni naskah kurikulum Prodi Pendidikan Bahasa Inggris (PBI dan Prodi Pendidikan Bahasa Prancis (PBP). Naskah kurikulum yang dimaksud adalah Kurikulum Program Studi Tahun 2014 FBS UNY. Instrumen berupa peneliti sebagai instrumen (human instrument) dilengkapi dengan lembar analisis untuk menelaah dokumen. Analisis data dilakukan secara deskriptif kualitatif dengan menggunakan metode baca dengan teknik pencermatan dokumen dan catat dengan teknik merekam secara tertulis dari hasil membaca terkait dengan profil lulusan, capaian pembelajaran, kompetensi, dan model pembelajaran. Kredibilitas penelitian dicapai melalui reliabilitas interater. Untuk menyederhanakan data, data hasil analisis kualitatif ditampilkan dalam data kuantitatif. Hal ini dimaksudkan agar data yang diperoleh memiliki keajegan dan penafsirannya tidak menyimpang dari objektivitas data. Penyajian data menggunakan model tabulasi verbal. Supaya dapat singkat dan sederhana, data-data verbal ditampilkan dalam bentuk angka berupa frekuensi munculnya suatu rumusan capaian pembelajaran pada suatu profil lulusan. 


\section{HASIL PENELITIAN DAN PEMBAHASAN}

Hasil penelitian berisi deskripsi hasil evaluasi yang berisi paparan mengenai Profil Lulusan (PL), Capaian Pembelajaran (CP): Kompetensi (K) Sikap (S), Penguasaan Pengetahuan (PP), Keterampilan Khusus (KKh), dan Keterampilan Umum (KU), dan Model Pembelajaran (MP) serta relevansi PL dengan CP dan MP pada kurikulum program studi PBI di FBS UNY.

Tabel 1 menunjukkan bahwa data dapat dimaknai sebagai berikut. Pertama, Program Studi Pendidikan Bahasa Inggris atau Prodi PBI merumuskan PL ke dalam delapan jenis. Dari delapan jenis tersebut yang memiliki relevansi dengan realitas profesi di dunia kerja hanya ada empat, yakni PL Pendidik, Peneliti, Penulis, dan Penerjemah (BPS, 2002), sedangkan PL yang lain lebih tepat jika dikategorikan atau disetarakan dengan nama mata kuliah. Di sisi lain, PL yang sangat dekat dengan keilmuan program studi, seperti ahli bahasa dan ahli interpretasi bahasa tidak terumuskan sebagai PL di prodi. Kedua, capaian pembelajaran (CP) yang mencakup CP-S, CP-PP, CP-KKh, dan CP-KU berdasarkan jumlahnya dirinci sebagai berikut. Jumlah rumusan CP-S 11 untuk delapan PL (setiap PL memiliki rumusan CP-S sama), CP-PP ada 18 rumusan, $\mathrm{CP}-\mathrm{KKh}$ ada 17 , dan $\mathrm{CP}-$ KU ada 7. Sebaran jumlah $\mathrm{CP}$ pada setiap PL bervariasi. Proporsi CP S dengan PL yang relevan tegolong baik karena semua CP-S harus dimiliki oleh PL. Hal senada juga terkait dengan proporsi CP PP, CP $\mathrm{KKh}$, dan $\mathrm{CP} \mathrm{KU}$ yang relevan dengan PL tergolong baik. Namun, salah satu PL yang tidak relevan memiliki CP yang lebih banyak daripada PL utama, yakni mencapai enam untuk semua CP selain SP S. Hal lain adalah CP-KU hanya muncul untuk PL Pendidik. Ketiga, MP yang dirumuskan di dalam kurikulum hanya berisi informasi pembelajaran berpusat pada mahasiswa dengan bentuk perkuliahan berupa tatap muka, penugasan terstruktur, dan mandiri, tetapi tidak ada satu pun rumusan model

Tabel 1

Relevansi PL, K, CP dengan MP pada Kurikulum Prodi PBI

\begin{tabular}{|c|c|c|c|c|c|c|}
\hline \multirow{2}{*}{ PROFIL LULUSAN } & \multicolumn{4}{|c|}{ Kompetensi } & \multirow{2}{*}{ MP } & \multirow{2}{*}{ Ket. } \\
\hline & CP-S & CP-PP & $\mathrm{CP}-\mathrm{KKh}$ & CP-KU & & \\
\hline Pendidik & 11 & 4 & 2 & 7 & TR & $\mathrm{R}$ \\
\hline Peneliti & 11 & 2 & 2 & 0 & TR & $\mathrm{R}$ \\
\hline Penulis buku ajar & 11 & 1 & 1 & 0 & TR & $\mathrm{R}$ \\
\hline Pengembang perangkat penilaian & 11 & 1 & 1 & 0 & TR & TR \\
\hline Pengembang program pembelajaran & 11 & 6 & 6 & 0 & TR & TR \\
\hline $\begin{array}{l}\text { Pengembang program pembelajaran untuk } \\
\text { anak-anak }\end{array}$ & 11 & 1 & 1 & 0 & TR & TR \\
\hline Penerjemah & 11 & 2 & 1 & 0 & TR & $\mathrm{R}$ \\
\hline Penyedia layanan Bahasa Inggris (bisnis) & 11 & 1 & 1 & 0 & TR & $\mathrm{TR}$ \\
\hline Jumlah CP & 11 & 18 & 17 & 7 & TR & TR \\
\hline
\end{tabular}

Keterangan: Prodi=Program Studi, $\mathrm{PBI}=$ Pendidikan Bahasa Inggris, $\mathrm{PL}=$ Profil Lulusan, $\mathrm{K}=$ Kompetensi, $\mathrm{CP}=$ Capaian Pembelajaran, $\mathrm{MP}=$ Model Pembelajaran, $\mathrm{S}=$ Sikap, $\mathrm{PP}=$ Penguasaan Pengetahuan, $\mathrm{KKh}=$ Keterampilan Khusus, $\mathrm{KU}=$ Keterampilan Umum, $\mathrm{R}=$ Relevan, $\mathrm{TR}=$ Tidak Relevan 
pembelajaran di dalam SN-Dikti Nomor 44 Tahun 2015 yang dikembangkan di dalam kurikulum. Berdasarkan SN-Dikti Nomor 44 Tahun 2015 model pembelajaran dalam kurikulum konseptual meliputi bentuk (kuliah, responsi/tutorial, seminar, dan praktikum) dan metode perkuliahan (berbasis masalah, berbasis proyek, penelitian, dan pengabdian).

Hasil penelitian berisi deskripsi hasil evaluasi yang berisi paparan mengenai Profil Lulusan (PL), Capaian Pembelajaran (CP): Kompetensi (K) Sikap (S), Penguasaan Pengetahuan (PP), Keterampilan Khusus (KKh), dan Keterampilan Umum (KU), dan Model Pembelajaran (MP) serta relevansi PL dengan CP dan MP pada kurikulum program studi PBP di FBS UNY.

Tabel 2 menunjukkan bahwa data dapat dimaknai sebagai berikut. Pertama, Program Studi Pendidikan Bahasa Prancis atau Prodi PBP merumuskan PL ke dalam tiga jenis. Semua PL relevan dengan realitas profesi di dunia kerja. Kedua, proporsi CP $\mathrm{S}$ dengan PL yang relevan tegolong baik karena semua CP S harus dimiliki oleh PL. Namun, tidak semua PL memiliki CP. Misalnya, PL penerjemah dan pemandu wisata untuk CP PP, CP KKh, dan CP KU. Ketiga, MP yang dirumuskan di dalam kurikulum hanya berisi informasi bentuk perkuliahan berupa tatap muka dan praktikum, tetapi tidak ada satu pun rumusan model pembelajaran di dalam SN-Dikti Nomor 44 Tahun 2015 yang dikembangkan di dalam kurikulum. Berdasarkan SN-Dikti Nomor 44 Tahun 2015 model pembelajaran dalam kurikulum konseptual meliputi bentuk (kuliah, responsi/tutorial, seminar, dan praktikum) dan metode perkuliahan (berbasis masalah, berbasis proyek, penelitian, dan pengabdian).

Berdasarkan temuan problematika dalam kurikulum yang meliputi penentuan PL yang masih belum disesuaikan dengan dunia kerja; CP untuk PP, KKh, dan KU yang belum proporsional; bahkan belum semua PL memiliki CP; model pembelajaran yang belum sesuai dengan standar nasional pendidikan, serta PL yang belum relevan dengan CP. Kasus pada Prodi PBI, misalnya, pada KU, yang relevan hanya dengan PL sebagai pendidik. PL terkait dengan penulis buku ajar, pengembang perangkat penilaian, pengembang program pembelajaran bahasa Inggris, pengembang program pembelajaran bahasa Inggris untuk anak-anak, penerjemah, peneliti, dan penyedia layanan bahasa Inggris (bisnis) tidak ada di dalam rumusan CP. Kompetensi KU dan CP seharusnya dirumuskan oleh prodi atau asosiasi. Sementara itu, di dalam kurikulum PBP semua CP keterampilan umum hanya relevan dengan PL sebagai

Tabel 2

Relevansi PL, K, CP dengan MP pada Kurikulum Prodi PBP

\begin{tabular}{lccccccc}
\hline \multirow{2}{*}{\multicolumn{1}{c}{ PROFIL LULUSAN }} & \multicolumn{5}{c}{ Kompetensi } & \multirow{2}{*}{ MP } & Ket. \\
\cline { 2 - 5 } & CP S & CP PP & CP KKh & CP KU & & \\
\hline Pendidik & 11 & 6 & 5 & 6 & TR & R \\
Penerjemah & 11 & 0 & 1 & 0 & TR & R \\
Pemandu Wisata & 11 & 0 & 1 & 0 & TR & R \\
\hline Ket: Prodinn
\end{tabular}

Ket.: Prodi=Program Studi, $\mathrm{PBP}=$ Pendidikan Bahasa Prancis, $\mathrm{PL}=$ Profil Lulusan, $\mathrm{K}=$ Kompetensi, $\mathrm{CP}=$ Capaian Pembelajaran, $\mathrm{MP}=$ Model Pembelajaran, $\mathrm{S}=$ Sikap, $\mathrm{PP}=$ Penguasaan Pengetahuan, $\mathrm{KKh}=$ Keterampilan Khusus, $\mathrm{KU}=$ Keterampilan Umum, $\mathrm{R}=$ Relevan, $\mathrm{TR}=$ Tidak Relevan 
pendidik. Padahal, PL meliputi pemandu dan penerjemah. Artinya, pada tahapan KU yang paling mendasar, rumusan kurikulum masih lemah. Terkait dengan model pembelajaran, rumusan MP pada prodi PBP baru berupa aktivitas per sks dilaksanakan melalui tatap muka dan praktikum. Tidak ada informasi yang mencukupi terkait dengan model pembelajaran seperti yang dirumuskan di dalam SN-Dikti Nomor 44 Tahun 2015.

Berdasarkan analisis terhadap kurikulum di Prodi FBS UNY, yakni Prodi PBI dan Prodi PBP ditemukan bahwa kelengkapan rumusan penguasaan pengetahuan, keterampilan khusus, dan keterampilan umum masih belum memadai (kecuali untuk kompetensi sikap); relevansi antara kompetensi sikap, penguasaan pengetahuan, keterampilan khusus, dan keterampilan umum dengan capaian pembelajaran dan profil lulusan masih belum memadai; serta pembelajaran belum dielaborasi berdasarkan model-model inovatif.

Persoalan tersebut mengandung dua perspektif. Perpsektif pertama masalah kemampuan merumuskan profil lulusan dan capaian pembelajaran. Rumusan profil lulusan tidak bisa dilepaskan dari dunia kerja. Secara umum profil lulusan program studi pendidikan bahasa adalah sebagai pendidik atau guru. Profil ini menjadi tumpuan pada kedua program studi yang diteliti. Namun, munculnya turunan profil lulusan yang cukup banyak, misalnya mencapai 8 PL untuk PBI dan 3 untuk PBP, belum didasarkan kajian dengan dunia kerja (BPS, 2002). PBI membuat 8 PL yang meliputi pendidik dengan $4 \mathrm{CP}$, peneliti $2 \mathrm{CP}$, penulis buku ajar dengan $1 \mathrm{CP}$, pengembang perangkat penilaian dengan $1 \mathrm{CP}$, pengembang program pembelajaran dengan $6 \mathrm{CP}$, pengembang program pembelajaran untuk anak dengan $1 \mathrm{CP}$, penerjemah $1 \mathrm{CP}$, dan penyedia layanan bahasa (bisnis) dengan 1 CP. Penamaan PL belum dipertimbangkan dari segi realitas dunia kerja yang diakui publik. Publik mengakui profesi pendidik, penulis, dan penerjemah, tetapi tidak ada profesi pengembang program pembelajaran (bahkan tampak dipaksakan dengan adanya PL pengembang program pembelajaran untuk anak-anak). Begitupun dengan pengembang perangkat penilaian dan penyedia layanan bahasa yang dijadikan PL prodi PBI lebih tepat dijadikan sebagai CP daripada PL.

Jika dibandingkan dengan Prodi PBP, ada perbedaan yang muncul. Pada Prodi PBP, PL mencakup pendidik dengan 6 $\mathrm{CP}$, pemandu wisata dengan $0 \mathrm{CP}$, dan penerjemah dengan $0 \mathrm{CP}$. Artinya, PL pada Prodi PBP dibuat lebih sederhana dengan mempertimbangkan nama profesi yang ada dalam dunia kerja (Badan Pusat Statistik, 2002). Persoalan yang muncul adalah tidak adanya CP pada PL pemandu wisata dan penerjemah. Jika CP tidak ada pada kedua PL tersebut, tentulah kompetensi lulusan tidak menggambarkan kapasitas yang memadai untuk menjadi penerjemah dan pemandu wisata. Padahal, Tubiyono (2013) menyatakan bahwa tuntutan capaian pembelajaran menjadi catatan penting dalam pasar kerja. Hasil risetnya menunjukkan bahwa peluang kesempatan kerja yang besar mempersyaratkan lulusan dengan kualitas tinggi, baik di level nasional maupun multinasional dengan menetapkan standar kualifikasi bahasa yang baik dengan karakter tanggung jawab, memiliki ide-ide kreatif dan inovatif.

Perspektif kedua yang menarik untuk dibahas adalah model pembelajaran yang dirumuskan kedua prodi tersebut. Berdasarkan SN-Dikti Nomor 44 Tahun 2015, model pembelajaran dalam kurikulum konseptual meliputi bentuk (kuliah, 
responsi/tutorial, seminar, dan praktikum) dan metode perkuliahan (berbasis masalah, berbasis proyek, penelitian, dan pengabdian). Di dalam kurikulum yang disusun hanya berupa informasi terkait pembelajaran yang berpusat pada mahasiswa serta aktivitas per sks, yakni tatap muka, tugas mandiri, tugas terstruktur, sifat perkuliahan. Namun, elaborasi atas pembelajaran inovatif yang dirumuskan di dalam SN-Dikti belum dilakukan sehingga kurikulum hanya berisi daftar mata kuliah, belum dilengkapi komponen lainnya sebagai dasar implementasi.

Di dalam kurikulum, selain visi-misi, profil lulusan, capaian pembelajaran, dan daftar mata kuliah juga harus ditampilkan model dan evaluasi pembelajaran. Model pembelajaran inovatif menjadi semacam ikon di abad ke-21 atau di Era Revolusi Industri 4.0. Kemampuan pengajar dan mahasiswa untuk berpikir kritis, inovatif, komunikatif, dan kolaboratif menjadi bagian yang utama untuk mencapai proses yang optimal. Luaran dari belajar bukan hanya pembelajar memiliki kompetensi, tetapi yang utama adalah kapabilitas. Kapabilitas akan melampaui kompetensi. Kompetensi hanya menjadi bagian dari kapabilitas.

Dalam beberapa kajian dijelaskan bahwa pendidikan memiliki peran strategis dalam menyiapkan generasi masa depan. Haryono, Subkhan, dan Widhanarto (2017) menjelaskan bahwa salah satu tugas pendidikan adalah menciptakan kompetensi pada diri pembelajar agar memiliki karakter kuat, terampil, kreatif, inovatif, technopreunership, dan peka lingkungan. Tugas ini dapat diejawantahkan melalui kurikulum yang memadai.

Wahyudin (2015) menyatakan bahwa terdapat tiga hal penting yang harus menjadi asumsi dalam menata kurikulum program studi pendidikan. Pertama, karier guru profesional sepatutnya dipahami sebagai sebuah proses berkesinambungan, berlangsung lama, dan perlu pembinaan yang berkelanjutan. Kedua, pembaharuan pendidikan guru profesional harus bertolak dari upaya penciptaan koherensi dalam kurikulum pendidikannya, baik secara struktural maupun konseptual agar dapat diperoleh program pendidikan guru yang lebih mantap. Ketiga, manajemen kurikulum memberi pengaruh siginifikan kepada alir an dan mata rantai pembelajaran dan budaya akademik bagi program pendidikan guru yang berkualitas dan bermartabat. Oliva (2016, p. 7) memastikan bahwa kurikulum perlu dipersepsi sebagai alat rekonstruksi pengetahuan secara sistematis.

Prodi-prodi pendidikan bahasa yang diteliti di FBS UNY berkategori prodi yang menyelenggarakan pendidikan akademik dalam bidang pendidikan bahasa. Proses pendidikan akademik berorientasi pada peningkatan pengetahuan dan keterampilan mengajar melalui tiga hal utama, yakni transfer pengalaman mengajar dalam setting otentik; pemaduan teori dan praktik belajar cara mengajar (learning to teach) dalam konteks latihan praktik (practice in practice); dan berlangsung secara kolaboratif di dalam komunitas profesional. Hal ini menunjukkan bahwa model pembelajaran di dalam kurikulum harus mampu mewadahi harapan-harapan tersebut.

Dalam perspektif pengembangan pembelajaran, kurikulum yang inovatif menjadi media transformasi para pembelajar dalam mengembangkan kemampuan memecahkan masalah berdasarkan metode ilmiah dan berpikir reflektif, seperti dikemukakan Oliva (2016, p. 35) bahwa kurikulum merupakan cara terpenting dalam memfasilitasi pembelajar untukmemecahkan masalah secara reflektif, ilmiah, dan juga sebagai cara belajar yang terprogram. Hal ini sejalan dengan dua pandangan 
tentang kurikulum, yakni kurikulum yang berpijak pada konteks dan kurikulum yang berpijak pada strategi (Wahyudin, 2016). Dalam perspektif konteks, pembelajaran dipandang sebagai pewarisan budaya bagi generasi muda untuk menghadapi kehidupan di masa yang akan datang, sedangkan sebagai strategi, pembelajarn dipandang sebagai proses. Kedua sudut pandang ini relevan dengan penciptaan kurikulum yang berorientasi ke masa depan.

Ada hal menarik untuk dijadikan bahan refleksi terkait dengan pembelajaran berbasis kurikulum yang berorientasi pada masa depan, yakni menautkan proses pembelajaran dengan lima pilar UNESCO (2009) yang meliputi learning to know, learning to do, learning to be, learning to live together, and learning to transform one self and society. Kurikulum dengan tatanan yang memadai memungkinkan pembelajar mampu mengonstruksi pengetahuan, memanfaatkan pengetahuan untuk kehidupan, baik untuk dirinya maupun lingkungan masyarakat. Debono (2015) menjelaskan bahwa setiap individu memiliki kemampuan mengelola dirinya menuju kemajuan yang tumbuhkembang secara adaptif (self-organizing system). Artinya, rumusan dalam kurikulum harus mampu memfasilitasi pembelajar untuk mengaktualisasikan dirinya di tengahtengah masyarakat. Kurikulum harus mampu memfasilitasi terjadinya proses pembelajaran yang menginspirasi, menumbuhkan dan memperkuat rasa keingintahuan (curiosity) mahasiswa terhadap sesuatu (Maksum, 2015, p. 2). Rasa keingintahuan yang kuat akan menumbuhkan budaya belajar, keberanian bertanya, dan keinginan mencipta. Visi yang demikian yang menyebabkan Singpura, Korea, dan China, yaitu how to instill a culture of enquiry and critical thinking into their education systems (Leslie, 2014) menjadi negara maju dengan sistem pendidikan yang unggul, termasuk di dalamnya kurikulum.
Sayangnya rumusan-rumusan dalam dua kurikulum prodi yang diteliti masih belum berorientasi pada capaian pembelajaran, melainkan masih berbasis pada content based curriculum. Kondisi ini tentunya menjadi kendala bagi penciptaan para pembelajar yang terdidik, mampu menggunakan akal sehat, mampu berpikir kritis dan inovatif, mampu menjadi pencari solusi atas masalah, mampu mengambil keputusan secara tepat. Yang terjadi adalah sikap yang selalu tergantung kepada orang lain. Sebagai contoh, di era pandemi korona kesiapan belajar mahasiswa dengan daring jarak jauh teramat sulit untuk dijalankan secara optimal. Berbagai kendala dihadapi mahasiswa, seperti soal kuota dan jaringan internet. Namun, secara umum persoalan yang mengemuka adalah masalah kesiapan belajar mandiri yang belum tercipta dengan baik.

Kebijakan Pemerintah dengan lahirnya Perpres Nomor 8 Tahun 2012 tentang Kerangka Kualifikasi Nasional Indonesia (KKNI) dan Permenristekdikti Nomor 44 tahun 2015 tentang Standar Nasional Pendidikan Tinggi (SN-Dikti) mengindikasikan bahwa pendidikan tinggi harus mampu melahirkan manusia Indonesia yang cakap, berkarakter, dan berdaya saing. Kurikulum menjadi salah satu komponen yang dapat membawa misi pencapaian harapan (visi) tersebut untuk menghadapi tantangan ke depan atau sebagai peta jalan menuju harapan, yakni manusia Indonesia yang hendak kita wujudkan (Maksum, 2015, p. 4). Perlu disadari bahwa tantangan generasi berubah dari waktu ke waktu, dan oleh karena itu pula, kurikulum tentu perlu menyesuaikan dengan kebutuhan zamannya. Lebih lanjut, Maksum (2015, p. 5) menjelaskan bahwa masalah yang saat ini dihadapi adalah persoalan "pergulatan" antara kurikulum sebagai dokumen dan kurikulum in action. Acapkali kurikulum 
sebagai dokumen telah tersusun dengan begitu baik, namun pelaksanaannya "jauh panggang dari api". Dalam konteks ini, peran pengelola kurikulum, dalam hal ini ketua program studi dan peran pelaksana kurikulum, yakni dosen serta mahasiswa, menjadi sangat urgen. Ada korelasi yang sangat kuat antara kepemimpinan akademik dan kualitas dosen terhadap keberhasilan pelaksanaan kurikulum. Artinya, semakin tinggi komitmen kepemimpinan akademik dan dosen dalam melaksanakan kurikulum, semakin tinggi pula peluang keberhasilan capaian-capaian kurikulum.

Dalam konteks penelitian ini, problematika yang ditemukan bahkan masih di tahap kurikulum sebagai dokumen. Temuan pada penelitian ini mengindikasikan bahwa masih belum adanya kesesuaian antara PL dengan CP dan MP sebagai bagian dari titik lemah kurikulum yang perlu segera ditata ulang. Problematika ini tentunya akan berdampak negatif terhadap kompetensi lulusan. Oleh karena itu, problematika penataan kurikulum dari segi kompetensi, capaian pembelajaran, profil lulusan, dan model pembelajaran harus segera dipecahkan. Di samping itu, problematika lain yang muncul adalah terkait dengan ketercapaian visi-misi-tujuan program studi dan pengelola program studi. Dengan temuan tersebut, optimalisasi pencapaian visi-misi-tujuan program studi dan pengelola program studi tidak dapat dilakukan secara efektif. Temuan ini juga menjadi tantangan bagi lembaga untuk melakukan terobosan baru agar rumusan kurikulum tidak menjadi ego sektoral lembaga, melainkan harus divalidasi melalui kesepakatan bersama antara kalangan perguruan tinggi, masyarakat profesi, dan pengguna lulusan.

Terdapat implikasi yang kuat bagi peningkatan mutu pembelajaran jika kurikulum dapat dirancang secara optimal.
Kondisi demikian berelasi dengan konsepsikonsepsi perkembangan IPTEKS. Seperti dipahami bersama bahwa universitas tidak steril dari tuntutan dan perkembangan zaman. Kemampuan menyikapi tantangan dan kecenderungan zaman menjadi standar bagi sebuah universitas untuk tetap kompetitif. Tantangan dan kecenderungan memaksa dan mengharuskan universitas untuk menerapkan logika korporasi dengan mengedepankan prinsip-prinsip efisiensi pembiayaan, perhitungan resiko, dan kemampuan prediktif (Baedowi, 2008). Untuk itulah, diperlukan pengerahan segenap potensi sumber daya universitas untuk melakukan inovasi.

Inovasi merupakan bagian dari validasi dan perluasan keilmuan yang bermanfaat. Salah satu aspek yang penting untuk diinovasi adalah kurikulum. Hal ini didasari oleh asumsi bahwa kurikulum merupakan salah satu komponen utama yang strategis di dalam sistem pendidikan. Asumsi ini memberikan dasar bahwa kurikulum tidak hanya berisi tujuan yang harus dicapai, melainkan juga memberikan pemahaman tentang pengalaman belajar bagi mahasiswa. Artinya, dalam perspekstif pembelajaran kurikukulum menjadi dasar yang kuat untuk menggerakkan komponenkomponen pembelajaran secara terintegrasi dan bermakna.

Di dalam konteks berbangsa dan bernegara kurikulum merupakan perangkat pembelajaran yang amat strategis untuk menyemaikan dan membentuk konsepsi dan perilaku individu tentang kesadaran identitas. Suwignyo (2007, p. 39) menyata-kan bahwa kesadaran identitas menunjuk pada kemampuan serta proses memahami perubahan jati diri terkait cara berpikir, kemandirian, dan orientasi pribadi (aspek internal-psikologis) serta posisi, peran, dan tanggung jawab sosial individu (aspek eksternal-sosiologis). 
Hasil penelitian menunjukkan bahwa perubahan dalam makna budaya dan praktik ditempatkan pada suatu transformasi, seperti bidang kehidupan manusia yang mencakup transformasi politik, ekonomi, dan religiusitas. Di samping itu, perubahan juga mencakup bidang pertanian, keuangan, kesehatan, fesyen, arsitektur, tata rumah, hukum, properti, dan subjektivitas yang harus dimengerti melalui kepedulian dan keterlibatan individu secara aktif untuk menyelesaikan masalah (Merry, 2003, p. 460).

Konsepsi tersebut sejalan dengan Pembukaan UUD 1945, yakni mencerdaskan kehidupan bangsa, melindungi segenap bangsa dan tumpah darah Indonesia, memajukan kesejahteraan umum, serta ikut melaksanakan ketertiban dunia yang berdasarkan perdamaian abadi dan keadilan sosial. Dengan kata lain, relevansi kurikulum dengan kesadaran identitas tercermin melalui pemaknaan yang mendalam bahwa pendidikan yang mencerdaskan adalah pendidikan dengan kurikulum yang mengarah pada pembangunan Indonesia menjadi negara bangsa yang maju, modern, bermoral, berdisiplin, beretos kerja tinggi, menguasai kemampuan teknis dan profesional, memiliki sikap rasional dan kemampuan intelektual, demokratis, bertanggung jawab, serta makmur dan sejahtera.

Di dalam perspektif pembelajaran, kurikulum bahasa merupakan seperangkat rencana yang berisi tujuan, isi, dan bahan pelajaran berbahasa dan bersastra serta cara yang digunakan sebagai pedoman penyelenggaraan kegiatan pembelajaran untuk mencapai tujuan pendidikan tertentu. Sesuai dengan konteks berbangsa dan bernegara, kurikulum dalam perspektif ini haruslah menjadi bagian dari penyemaian dan pembentukan konsepsi dan perilaku individu tentang kesadaran identitas kebangsaan dan kenegaraan. Dengan demikian, kurikulum bukan hanya menjadi hiasan selama pertemuan di ruang-ruang kelas antara dosen dengan mahasiswa, melainkan bagian terpenting di dalam mengubah karakteristik manusia Indonesia yang maju, modern, bermoral, berdisiplin, beretos kerja tinggi, menguasai kemampuan teknis dan profesional, memiliki sikap rasional dan kemampuan intelektual, demokratis, bertanggung jawab, serta makmur dan sejahtera.

Dalam era kekinian, tentulah produk kurikulum sudah harus mengalami perubahan seiring dengan lahirnya Peraturan Presiden Nomor 8 Tahun 2012 tentang Kerangka Kualifikasi Nasional Indonesia (KKNI) dan Standar Nasional Pendidikan Tinggi (SN-Dikti). Di dalam perubahan kurikulum berbasis KKNI dan SN-Dikti terdapat dua hal esensial, yakni profil lulusan serta capaian belajar (learning outcomes) atau sering disebut dengan standar kompetensi lulusan dan kualifikasi capaian.

Kedua dasar tersebut dijadikan landasan di dalam melakukan perubahan kurikulum pendidikan tinggi di Indonesia. Namun, persoalan yang muncul adalah tingkat pemahaman para penyusun kurikulum belum sepenuhnya memadai. Masih adanya ketidakselarasan antara satu komponen dengan komponen lain, seperti pemahaman di dalam merumuskan PL dan dielaborasi ke dalam CP serta MP yang belum selaras menunjukkan pemahaman yang kurang tadi. Akibatnya, belum semua gambaran PL relevan dengan dunia kerja. Hal senada juga terjadi di dalam merumuskan $\mathrm{CP}$. Tidak semua PL memiliki CP. Akibatnya, pembelajaran di level implementasi juga tidak akan selaras.

Diskusi berikutnya adalah terkait dengan orientasi capaian yang baru sampai di level kompetensi. Dalam perkembangan 
baru, kompetensi merupakan capaian yang masih berorientasi ke masa kini. Kamdi (2016, p. 15) menjelaskan bahwa terdapat tiga orientasi pendidikan tinggi, yakni training model, professional development model, dan capability development model. Model pertama dan kedua sangat populer dalam pendidikan ala industrial yang "mengeksploitasi" sumber daya manusia untuk tujuan reproduksi ekonomi melalui pendidikan. Teori efisiensi sosial yang menggambarkan bahwa kurikulum pendidikan didesain berbasis kompetensi dengan rujukan utama kebutuhan job pada area okupasi atau profesi tertentu. Tugas pendidikan adalah menjadikan proses secara efisien karena fiksasi cakupan kompetensi dalam kurikulum amat jelas, definitif, dan rigid. Sebaliknya, model ketiga tidak menggunakan job atau profesi tertentu sebagai rujukan utama pendidikan, melainkan menggunakan kekuatan potensial individu sebagai rujukan utama pendidikan. Orientasi pendidikan dengan model ketiga adalah pengembangan kapabilitas yang melampaui kompetensi. Mencermati dasar perubahan kurikulum pendidikan tinggi yang demikian mencerminkan bahwa praksis pendidikan tinggi di Indonesia masih menggunakan model pertama dan kedua, yakni berbasis kompetensi, dan dominasi model training untuk menyiapkan mahasiswa sebagai calon pekerja. Namun, model kapabilitas masih belum menjadi visi di masa depan.

Model ketiga ini telah mendekonstruksi popularitas dua model pertama. Kebutuhan belajar berubah dari memenuhi blueprint profesi manusia yang diturunkan dari definisi peran sosial atau profesi tertentu bergeser ke aras pengembangan kapabilitas peserta didik untuk menciptakan profesi yang berpusat pada keunggulan personalnya (Kamdi, 2016, pp. 15-16). Di samping itu, dunia profesi mengalami dinamika kehidupan yang tidak mudah lagi diprediksi yang mengakibatkan makin kaburnya definisi peran sosial. Kompetensi merupakan unsur penting dari kapabilitas. Namun, orang yang kapabel adalah mereka yang dapat berbuat secara efektif dalam konteks yang tidak diketahui atau masalah baru. Untuk bisa menjadi kapabel, orang membutuhkan pengalaman belajar yang berbeda dengan belajar kompetensi. Kemampuan belajar bagaimana cara belajar, nilai dan kepercayaan diri, misalnya, tidak dapat dicapai hanya dengan menggunakan pendekatan perilaku sederhana. Berbagai pendekatan perilaku menjadi sangat penting untuk dikembangkan di dalam perspektif pembelajaran inovatif.

Dalam perspektif pembelajaran inovatif, kurikulum harus sesuai dengan prinsip proses perkuliahan (kesesuaian proses dengan karakteristik mata kuliah, keberagaman metode yang mengakomodasi perbedaan individu mahasiswa, penataan tingkat kesulitan, mengatur interaksi dan partisipasi mahasiswa, menekankan berbagai variasi belajar, dan mendorong kemampuan baru) serta dapat lebih mengaktifkan interaksi kelas (Sukmadinata, 2007, pp. 152-153). Untuk mencapai perspektif tersebut, model pembelajaran dalam kurikulum haruslah memiliki berbagai alternatif pembelajaran, bentuk pembelajaran (kuliah, responsi/tutorial, seminar, dan praktikum) dan metode perkuliahan (berbasis masalah, berbasis proyek, penelitian, dan pengabdian). Hal ini sejalan dengan hakikat kurikulum bahwa kurikulum merupakan komponen utama pendidikan dan sebagai pedoman pembelajaran. Jika antarsubkomponen kurikulum disusun secara baik, proses pembelajaran akan selalu merujuk kepada kurikulum yang baik. Hal-hal inilah yang menjadikan perubahan kurikulum memiliki esensi bahwa kurikulum yang berorientasi 
ke masa depan haruslah menjadikan pembelajaran bahasa yang bermakna bagi lahirnya insan-insan berkualitas.

\section{SIMPULAN}

Simpulan hasil penelitian ini adalah sebagai berikut. Pertama, profil lulusan belum dirumuskan berdasarkan realitas profesi yang ada di lapangan sehingga belum secara optimal dapat memberikan pemahaman tentang pengalaman belajar yang dirumuskan melalui capaian pembelajaran. Kedua, kompetensi belum dielaborasi secara lengkap dan relevan ke dalam capaian pembelajaran, profil lulusan, dan model pembelajaran sehingga kurikulum belum dijadikan perangkat pembelajaran strategis untuk menyemaikan dan membentuk konsepsi dan perilaku individu tentang keilmuan program studi. Ketiga, rumusan kompetensi sikap sudah menjadi bagian dari penyemaian dan pembentukan konsepsi dan perilaku individu tentang kesadaran identitas kebangsaan dan kenegaraan. Namun, kompetensi penguasaan pengetahuan, keterampilan khusus, dan keterampilan umum belum sepenuhnya lengkap dan relevan dengan pembentukan kesadaran keilmuan bidang bahasa dan sastra yang berorientasi ke masa depan. Rekomendasinya yang dapat diajukan adalah revisi kurikulum secara terstuktur menjadi bagian penting bagi peningkatan mutu lulusan program studi pendidikan bahasa dengan mendasarkan pada isu-isu terbaru dalam pekermbangan IPTEKS.

\section{DAFTAR PUSTAKA}

Amir, M. F. (2010, Januari). Membangun kesiapan sistem penjaminan mutu eksternal (SPME) bagi perguruan tinggi di Indonesia. Makalah dipresentasikan pada Lokakarya persiapan SPME. UM, Sumatera Utara.
Badan Pusat Statistik. (2002). KBJI 2002: Klasifikasi jenis pekerjaan Indonesia. Jakarta: Badan Pusat Statistik.

Baedowi, A. (2010). Tantangan dan tren pendidikan tinggi dalam nasionalnya pendidikan kita. Jakarta: Kemdiknas

BAN-PT. (2007). Akreditasi institusi PT: buku V pedoman penilaian portofolio akreditasi instititusi perguruan tinggi. Jakarta: Depdiknas.

Debono, E. (2015). Serious creativity: How to be creative under pressure and turn ideas into action. London: Vermilion.

Haryono, Subkhan, E., \& Widhanarto, G. P. (2017). $21^{\text {st }}$ Century competencies and its implications on educational practices. Advances in Social Science, Educational and Humanities Research, $118,606-610$.

Kamdi, W. (2016). Inovasi pendidikan tinggi. Orasi Ilmiah dalam rangka Dies Natalis UNM ke-62. UNM, Malang.

Leslie, I. (2014). Curious: The desire to know and why your future depends on it. London: Quercus.

Maksum, A. (2015, April). Kurikulum dan pembelajaran di perguruan tinggi: menuju pendidikan yang memberdayakan. Makalah dipresentasikan pada Seminar Nasional Hasil Penelitian Pendidikan dan Pembelajaran. STKIP PGRI, Jombang

Merry, S.E. (2003), Hegemony and culture in historical anthropology: A review esaay on Jean and John L Commaroff's of revelation and revolution. The American Historical Review, 108(2), 460-470. https://doi.org/10.1086/ $\mathrm{ahr} / 108.2 .460$.

Oliva, P. F. (2016). Developing curriculum ( $8^{\text {th }}$ ed.). New York: Harper Collins Publishers.

PDPT UNY. (2017). Akreditasi program studi. Diunduh dari http://pdpt.uny. ac.id/. 
Sukmadinata, N. S. (2007). Pengembangan kurikulum: Teori dan praktek. Bandung: Remaja Rosdakarya.

Suwignyo. (2007). Kurikulum dan politik kebijakan pendidikan. Dalam Forum Mangunwijaya, Kurikulum yang mencerdaskan: Visi 2030 dan pendidikan alternatif. Jakarta: PT Kompas Media Nusantara.

Tubiyono. (2013). Peta bahasa expose poster pusat pembinaan karier dan kewirausahaan sebagai penyempurnaan kurikulum perguruan tinggi. Sirok
Bastra, 1(1), 59-70. Diunduh dari http://sirokbastra.kemdikbud.go.id/ index.php/sirokbastra/article/view/6/5.

UNESCO. (2009). Education for sustainable development. France: Division for the coordination of United Nations priorities in education.

Wahyudin, D. (2016). Manajemen kurikulum dalam pendidikan profesi guru: Studi kasus di Universitas Pendidikan Indonesia. Jurnal Kependidikan, 46(2), 259-270. 